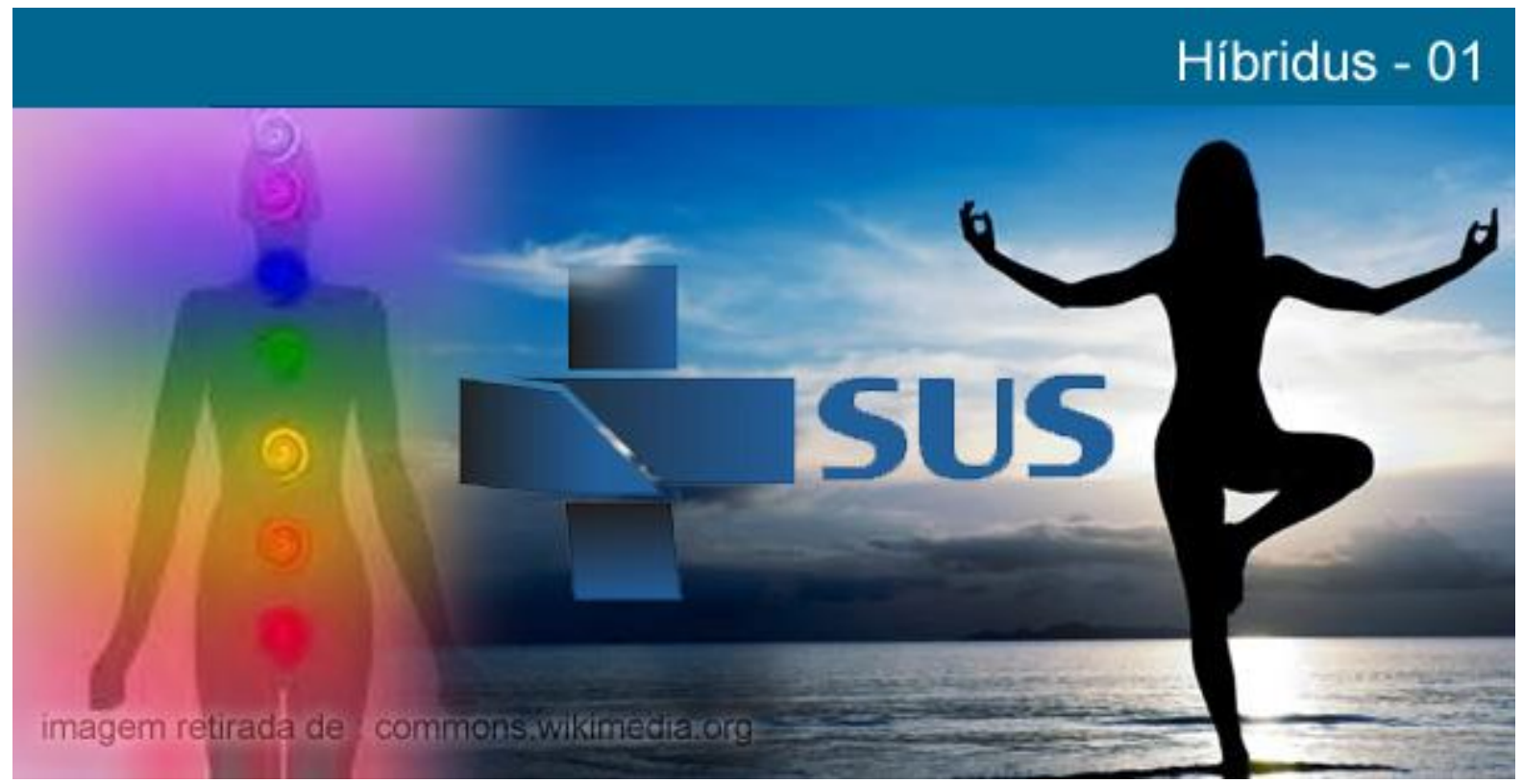

\title{
TERAPIA ATRAVÉS DO MOVIMENTO COMO DISPOSITIVO DE CUIDADO NO SUS ${ }^{1}$
}

\section{Mariana Machado Tinoco}

Psicóloga formada pela Universidade Federal Fluminense. Mestre em Saúde Pública pela Escola Nacional em Saúde Pública (ENSP/Fiocruz), Pós-graduada em Gestão em Saúde Pública pela Universidade Federal Fluminense (UFF) e especialista em Terapia Através do Movimento pela Faculdade Angel Vianna.

Resumo: As práticas integrativas e complementares (PIC) são dispositivos e práticas de cuidado que atuam de forma diferente do enfoque biologicista e fragmentário da biomedicina, centrado nas doenças. As PIC operam no campo da prevenção de agravos e da promoção, manutenção e recuperação da saúde, baseando-se na integralidade do indivíduo. O presente artigo pretende apresentar a Terapia Através do Movimento (TAM) como uma aposta ao enriquecimento das Práticas Integrativas e Complementares (PIC) para produção de saúde. A Terapia Através do Movimento é inspirada na Conscientização do Movimento, método desenvolvido por Angel Vianna, que Maria Helena Imbassaí nomeia de Conscientização Corporal, trata-se de uma prática corporal e um trabalho de conscientização, que abordará técnicas de relaxamento e micro movimentos que levarão à consciência do corpo. O objetivo deste artigo é apresentar a TAM como dispositivo de cuidado para a promoção da saúde na atenção básica e no fortalecimento do sistema único de saúde (SUS).

Palavras-chave: Terapias complementares. Atenção primária a saúde. Atenção básica. Integralidade em saúde.

\section{THERAPY THROUGH THE MOVEMENT AS A TOOL FOR CARE OF THE SUS (UNIFIED HEALTH SYSTEM)}

Abstract: The Complementary Integrative Practice (PIC) are tools and practices of health care, which act, differently from the biologist focus and fragmentary biomedicine centered on diseases. The PIC cooperates in disease prevention and promotion, support and recovering of health. It is based on the integrality of the individual. The present article presents Therapy Through the Movement (TAM) as a contribution to the Complementary Integrative Practice (PIC). Therapy Through the Movement, is inspired in a method developed by Angel Vianna, who Maria Helena Imbassaí names as Body Awareness. It is a body exercise and an awareness work that incorporates techniques of relaxation and micro movements, which enhances body consciousness. The

\footnotetext{
${ }^{1}$ Agradecimentos aos alunos e professores da Escola e Faculdade de Dança Angel Vianna.
}

\section{POLÊM!CA | Revista Eletronica da Ueji}


purpose of this article is to present TAM as a tool for care and promotion of health in the primary attention and strengthening of the "Sistema Único de Saúde" - SUS (Unified Health System).

Keywords: Complementary Therapies. Primary Health Care. Integrality in Health.

\section{Introdução}

A Terapia Através do Movimento (TAM) é um trabalho de conscientização e atenção corporal que através de técnicas de relaxamento e micro movimentos leva à consciência dos músculos, dos ossos, das articulações, ou seja, do próprio corpo.

A proposta da TAM é atuar sobre o aparato corporal de modo a sensibilizá-lo, permitindo-lhe observar que dentro de si existe uma energia impulsionada por um ritmo que lhe confere dinâmica, estimulando a propriocepção, ou seja, a sensibilidade e a autorregulação dos tônus, ossos, músculos, tendões e articulações, informando o corpo sobre o equilíbrio e o deslocamento no espaço (VIANNA, CASTILHO, 2002).

Cada corpo traz consigo uma memória de vida, uma história, um contexto social, cultural e familiar. Uma memória que está impregnada nos músculos, nos ossos, nos tendões, nos órgãos, no padrão da respiração. Para Vianna e Castilho (2002), o corpo fala através do tônus da pele, do brilho dos olhos, do balançar dos quadris, do sorriso e do choro. Desta forma, a percepção do próprio corpo é o primeiro passo para entrarmos em contato conosco.

Vianna e Castilho (2002) ressaltam que o corpo é uma casa, em que o morador são nossos órgãos, nosso humor, nossos afetos, nossa memória, nossas emoções e inteligência. Para que nosso corpo seja um lugar gostoso de se morar é preciso que ele seja limpo, confortável, arejado e espaçoso (p.19). E se fizermos o uso inadequado dele, ele sinalizará através das dores, nevralgias, tensões e indisposições.

Ao mudarmos nossa relação com o próprio corpo, mudamos também nossa relação com o entorno e com o mundo. Podemos viver com maior bem-estar físico e mental quando desenvolvemos a nossa própria coordenação, com o emprego adequado da força, com a abertura de espaços internos e aceitação do próprio corpo e sua imagem, com suas limitações e potencialidades (NUNES, 2003).

A Terapia Através do Movimento é inspirada na Conscientização do Movimento, método desenvolvido por Angel Vianna - bailarina, coreógrafa e pesquisadora do movimento - que Imbassaí (2003) nomeará de Conscientização Corporal. Esse método trata de um trabalho de autorregulação e organização corporal que utiliza como técnicas o relaxamento, a

\section{POLÊM!CA | Revista Eletronica da verj}


consciência corporal através dos micromovimentos, a criatividade e a dança livre (IMBASSAÍ, 2003).

Angel Vianna é considerada a pioneira do movimento consciente junto com seu marido Klauss Vianna. Essa abordagem corporal ampliou os horizontes da dança e do teatro no Brasil, a partir de um olhar mais orgânico sobre a dança e sobre os estudos de anatomia, fisiologia e cinesologia (IMBASSAÍ, 2003).

O método de Angel Vianna de conscientização do movimento contribui para a formação de um ser humano sensível e consciente. Essa pesquisa sobre o movimento do corpo cria um espaço inaugural de reflexão e análise sobre si que possibilita nos constituir em um novo território existencial, um outro modo de se relacionar consigo e com o mundo.

Caetano, Resende e Torralba (2012), ao falarem de micropolítica do corpo, trazem à discussão a micropolítica que permite tornar visível o aspecto sensível e intensivo do corpo. Pensando neste aspecto, a Terapia Através do Movimento não trata apenas do cuidado de um corpo estático, mas de uma prática que pensa o corpo em movimento, corpo sensorial que vai ao encontro de várias sensações e experimentações.

Para Vianna, Castilho (2002) e Imbassaí (2003), conscientizar o seu próprio corpo é trabalhar o movimento com atenção para as sensações, conhecer a dinâmica, perceber a postura, a tonicidade e o equilíbrio do corpo.

O Ministério da Saúde apresenta as Práticas Integrativas e Complementares (PIC) como ações de cuidado que atuam no campo da prevenção de doenças e da promoção da saúde, baseando-se na integralidade do sujeito (BRASIL, 2006). Essas práticas estão direcionadas a uma produção de cuidado que não reduz o ser humano ao aparelho ou sistema biológico, e que prioriza uma escuta diferente do corpo.

Diante desse cenário, o objetivo deste artigo é apresentar a Terapia Através do Movimento (TAM) como um instrumento terapêutico nos campos das práticas integrativas e complementares em saúde, como dispositivo de cuidado e ferramenta para promoção da saúde no SUS.

\section{Novo paradigma da saúde pública brasileira}

Na década de 1980, surgiram propostas de modificação do sistema sanitário brasileiro, o que resultou no Sistema Único de Saúde (SUS). Antes do SUS, o sistema de saúde era

\section{POLÊM!CA | Revista Eletronica da Uer}


composto por uma visão dualista do processo de saúde-doença que direcionava as práticas sanitárias para uma assistência médica individual e curativista. A saúde não era considerada como direito universal, ou seja, seu acesso era restrito apenas a contribuintes do INSS, que, na época, eram separados por categoria profissional e recebiam atendimento específico de acordo com a categoria em que se inserissem.

Inspirada na Organização Mundial da Saúde (OMS, 1947), que define saúde como um estado de completo bem-estar físico, mental e social, e não apenas a ausência de doença ou enfermidade, a Constituição Federal Brasileira, de 1988, define saúde em seu Art. 196 como sendo um direito de todos e dever do Estado, garantido mediante políticas sociais e econômicas que visem à redução do risco de doenças e outros agravos e ao acesso universal e igualitário às ações e serviços para sua promoção, proteção e recuperação. Dessa forma, saúde seria, não apenas a ausência de doenças, mas também modos de viver, condições de trabalho, condições de habitação, ambiente, educação, lazer, cultura e acesso a bens e serviços essenciais.

Pensando nesse novo paradigma de saúde do Brasil, as práticas integrativas e complementares (PIC) se apresentam como dispositivos e práticas de cuidado que atuam de forma diferente do enfoque biologicista e fragmentário da biomedicina, centrado apenas nas doenças. As PIC operam no campo da prevenção de agravos e da promoção, manutenção e recuperação da saúde, baseando-se na integralidade do sujeito (BRASIL, 2006).

Da clínica biomédica centrada na doença e na cura, dá-se lugar ao trabalho em equipe visando à atenção integral das famílias no território onde elas vivem. Desta forma, compreende-se o processo saúde-doença e as necessidades locais, além da execução de práticas curativas, sobretudo a prevenção de doenças a fim de se promover saúde.

A integralidade é um dos princípios doutrinários do Sistema Único de Saúde (SUS) que se destina a ações direcionadas a um cuidado em que busca reconhecer as necessidades de saúde dos cidadãos, para além das demandas explícitas. O princípio da integralidade pressupõe o conceito de saúde ampliado que não reduz o indivíduo ao aparelho ou sistema biológico, superando a fragmentação das atividades nos serviços de saúde (BRASIL, 2010).

Esse novo paradigma de saúde, questiona os modos hegemônicos biomédicos, ou seja, atua diferentemente do enfoque biologicista e fragmentário da biomedicina, centrado nas doenças e na perspectiva medicalizante do cuidado.

\section{POLÊM!CA | Revista Eletronica da Ueri}


A Política Nacional de Práticas Integrativas e Complementares (PNPIC) teve sua aprovação a partir da portaria do Ministério da Saúde n.971/2006. A referida portaria instituiu no SUS a medicina tradicional chinesa, a homeopatia, a acupuntura, a fitoterapia, o termalismo e a medicina antroposófica como práticas integrativas e complementares de cuidado. Embora essas práticas estejam crescendo no nosso sistema de saúde, a PNPIC ainda é incipiente, pouco desenvolvida para o cuidado das pessoas na Atenção Primária à Saúde no SUS.

No entanto, essa abordagem holística que abrange o indivíduo como um todo, na sua integralidade e não apenas no seu sintoma, estimula o bem-estar, a qualidade de vida, promovendo saúde e prevenindo doenças. Esse novo paradigma da saúde brasileira possibilita que os cuidados sejam elaborados a partir do indivíduo em seu contexto, considerando a sua singularidade e sua história de vida, seus hábitos e seus costumes.

A TAM ainda não está instituída e não é apresentada como PIC. Entendemos essa prática corporal, alinhada ao princípio da integralidade priorizado pelo SUS, como instrumento terapêutico produtor de saúde e vida.

\section{A Terapia Através do Movimento como dispositivo de cuidado}

Corpo não é apenas uma forma em movimento correndo, nadando ou dançando. É menos ainda uma vitrine de marcas e logotipos. Instrumento do homem no mundo, o corpo é possibilidade permanente de invenção de novas finalidades e disposição para vivê-las. (IMBASSAÍ, 2003, p 47).

Conhecer nosso corpo requer uma disciplina que remete ao socrático "conhece-te a ti mesmo". Quando pesquisamos nosso movimento estamos simultaneamente provocando uma reeducação dos sentidos, dos sentimentos e da própria razão (NUNES, 2003). A Terapia Através do Movimento nos leva a ter um outro olhar sobre nós mesmos e sobre o mundo, aguça nossa percepção sensível, entendendo que diferença não é desvio e de que o corpo humano, independente de suas limitações, pode ser vivido e tratado na sua singularidade.

É desse lugar que queremos falar sobre a Terapia Através do Movimento, tendo o corpo como referencial concreto e como instrumento de comunicação do homem no mundo. No entanto, em alguns momentos ocorre o impedimento desse intercâmbio devido ao acúmulo de tensões provenientes de acontecimentos da vida, que enrijecem os músculos, bloqueiam as

\section{POLÊM!CA | Revista Eletronica da Ueri}


articulações, dificultam o fluxo sanguíneo, afetam a respiração, restringem os movimentos contribuindo para desestabilizar e dessensibilizar o organismo humano (IMBASSAÍ, 2003).

Vianna e Castilho (2002) utilizam a metáfora da manutenção de uma casa para falar sobre o cuidado do corpo:

\begin{abstract}
É bom abrir as janelas de vez em quando, deixar o ar circular, dar uma arejada. As dobradiças da janela, quando rangem, indicam que estão tendo pouco uso. As nossas dobradiças, também, rangem com pouco ou mau uso. São as articulações, responsáveis diretas pelo bom funcionamento de nossa estrutura básica (as paredes e o teto), o esqueleto. Sabe por quê? Porque as articulações possuem sensores, receptores sensíveis que "informam" ao cérebro como estão agindo e o que é preciso fazer para mover ossos, músculos e tecidos. Ou seja, elas são diretamente responsáveis por nossa mobilidade. E onde não há movimento não há vida, não há pulsação, não há processos se construindo e se desconstruindo continuamente. É preciso por óleo nessas dobradiças de vez em quando, para restituir-lhes a flexibilidade. Não, não é preciso tomar injeções de lubrificantes. Basta mover-se. (VIANNA, CASTILHO, 2002, p. 20).
\end{abstract}

Quando nos movemos, despertamos toda nossa estrutura corporal ativa-se a circulação de todos os fluidos, oxigena-se os tecidos, faz-se aumentar a produção do líquido sinovial líquido que lubrifica as articulações. Aqui não estamos falando de uma malhação desesperada e obrigatória, como nos é imposta hoje. Na falsa ideia de ter uma vida mais saudável, vendese um modo de viver obsessivo em busca de um corpo "ideal". Estamos falando de outra qualidade do movimento, de se mover com consciência e cuidado, com sutileza e com atenção, atento à maneira de se mover. De buscar novos caminhos, de estimular potencialidades, de perceber onde nasce e como repercute em todo o corpo o movimento, reaprendendo a se perceber (BULHÕES, 2009; VIANNA, CASTILHO, 2002).

Cada corpo é único traz consigo suas marcas, uma memória de vida, uma história, um contexto social, cultural e familiar. Há memórias que estão impregnadas nos músculos, nos ossos, nos tendões, nos órgãos, no padrão da respiração. A percepção do próprio corpo é o primeiro passo para entrarmos em contato conosco.

O corpo fala e traduz nossa história, atualiza nossos desejos e limites. O corpo fala de contínuas transformações que estão ocorrendo o tempo todo, porque consiste numa estrutura dinâmica em um contexto social, cultural e político. Em cada corpo existe uma maneira peculiar de se comunicar, de se fazer escutar.

Conscientizar sobre o seu próprio corpo é trabalhar o movimento com atenção para as sensações, a dinâmica, a postura, a tonicidade e o equilíbrio do corpo. Para chegar a este 
estado de presença sugere-se que primeiramente caminhe pelo local em que está, reconheça os objetos, as cores, a luminosidade, a temperatura ambiente, o chão, utilizando o chão como aliado para poder se apoiar, se espreguiçar, alongar, bocejar quando sentir vontade, deixando que os sons e suspiros aconteçam.

De acordo com Imbassaí (2003), uma aula de conscientização corporal compõe-se de quatro etapas e tem duração de 90 min divididos assim: espreguiçamento (10'), relaxamento consciente (10'), micro movimentos (50’), uso do espaço (20’). Todos esses itens são abordados sob o princípio de simultaneidade, o trinômio mover/sentir/pensar, indissociável nesse trabalho que proporciona a tomada de consciência das conexões entre os segmentos.

A proposta desse trabalho é atuar sobre o aparato corporal de modo a sensibilizá-lo, permitindo-lhe observar que dentro de si existe uma energia impulsionada por um ritmo, estimulando a propriocepção, ou seja, a sensibilidade própria dos ossos, dos músculos, tendões e articulações, informando sobre o equilíbrio e o deslocamento do corpo no espaço.

Sendo assim, essa pesquisa do movimento vai desde o espreguiçar, bocejar, relaxar, passando pelo momento de conscientização dos micros movimentos, da base dos pés ao ápice da cabeça, sentindo e percebendo a maneira que processamos os movimentos, resgatando a sensibilidade e a consciência do movimento no corpo. Pode-se utilizar objetos de diferentes texturas, temperaturas, formatos e pesos como a bola de tênis, o bambu, a espuma, a escova, os lenços, para ajudar na investigação. O último momento da aula compreende-se na dança livre ou jogos corporais, onde podemos improvisar, criar,e expressar nossa singularidade nos diferentes planos (baixo, médio e alto). Este é o momento em que nos movimentamos livremente ao som de uma música de fundo, sem nos preocuparmos com técnica específica. $\mathrm{O}$ desejável é que trabalhemos descalços e com roupas confortáveis.

Nesse processo de investigação que exige atenção vão se produzindo descobertas devido à abertura senso-perceptiva onde podemos perceber como se processam os movimentos, numa experiência sensível de resgatar a consciência. Como perceber que o chão é espaço de saúde, sustentação e criação. Um lugar de invenção improviso e contato que serve como ferramenta de investigação com o que acontece com o nosso corpo. O chão auxilia em conhecer as dobras para desdobrar e assim expandir, desdobrar para dentro de si conscientizando sobre os movimentos internos e externos, movimentos das vísceras e das

\section{POLÊM!CA | Revista Eletronica da Ueij}


articulações. Possibilitando que conheçamos as potencialidades e limites do nosso corpo, que desconhecíamos.

Segundo Imbassaí (2003), a conscientização corporal é um instrumento pedagógico, de caráter preventivo: sua proposta é abrir canais da percepção sensorial. Apresenta-se no formato de aula e não pretende competir com outras especialidades como a fisioterapia, psicoterapia ou musicoterapia, mas compor com elas. $\mathrm{O}$ objetivo dessa prática é trabalhar com elementos constitutivos de uma organização corporal saudável. Sua prática é considerada uma atividade terapêutica que ajuda a regular os níveis de estresse, identificar e equilibrar as tensões, corrigir as disfunções corporais, estimular o potencial criativo e tem como efeito o bem-estar, a funcionalidade corporal e o autoconhecimento.

Pensar em trabalhar com conscientização corporal ou consciência do movimento (trabalho que aqui nomeamos como Terapia Através do Movimento) é uma proposta possível, pois sua prática não exige nenhum pré-requisito, qualquer pessoa pode participar e é indicada principalmente aos que sofrem de estresse, doenças crônicas ou simplesmente aos que aspiram bem-estar e desenvolvimento pessoal (RESENDE, 2008; IMBASSAÍ, 2003).

Essa prática desperta o corpo para sensibilização e conexão com sua forma, seu volume, os espaços e tensões através da conscientização dos movimentos internos e externos, micro e macromovimentos, voluntários e involuntários, movimentos do corpo pulsante em suas variadas qualidades, pensando na expansão da vida. Promove a reposição de energia desgastada pelo estresse, a melhoria das condições posturais, da respiração, da circulação, da coordenação motora, da propriocepção, ou seja, o equilíbrio do organismo como um todo produzindo integração corpo-mente, promovendo saúde.

Essa prática não se resume apenas a 90 minutos de aula mas é um exercício constante de sensibilização e consciência onde reaprendemos a sentir com os olhos, com os ouvidos, com o nariz, com a boca, com a pele toda, a incansável maravilha do mundo em movimento, promovendo saúde a partir de um caldeirão de experimentações (TORRALBA, 2012:8; VIANNA, CASTILHO, 2002).

\section{Propondo Práticas}

Entendemos que é necessário articular e estimular a transformação das práticas de saúde no SUS tendo em vista a implementação de práticas alternativas às práticas

\section{POLÊM!CA | Revista Eletronica da Uej}


hegemônicas, que possam construir outros sentidos e olhares sobre o corpo, respeitando as diferenças que existem em cada corpo, evitando padronizações.

Nas sociedades contemporâneas urbanas podemos dizer que tem acontecido um fenômeno que chamamos de "dessensibilização". O corpo de cada um é, muitas vezes, ignorado e até mesmo excluído, por intermédio de práticas homogeneizantes, depreciativas e restritivas, caso não correspondam ao "padrão ideal", isto é, a imagem determinada por valores sociais, políticos e de mercado. É importante entendermos os valores sociais e culturais, mas não vivermos dominados por eles (BULHÕES, 2009).

Apesar da saúde representar uma das mais importantes demandas da cultura contemporânea, como um verdadeiro mercado do bem-estar, pronto a ser consumido em spas, academias, clínicas de estética etc, revela-se, também, a dificuldade em lidar com a dimensão sutil do corpo.

A Terapia Através do Movimento pretende resgatar essa sensibilização a partir do trabalho de atenção e de propriocepção. Por isso entende-se que essa prática seja reconhecida dentro da Política Nacional de Práticas Integrativas e Complementares compreendendo que a Conscientização do Movimento lida com a visão ampliada do processo saúde-doença e pressupõe o indivíduo em sua globalidade.

Primeiramente, entendemos que antes de aplicar qualquer técnica precisamos experimentá-las em nós mesmos. A partir dessa premissa, buscamos começar esse processo fazendo que essa experiência sensível seja primeiramente vivenciada pelos profissionais de saúde.

A intenção é sensibilizar os profissionais de saúde acerca do novo enfoque sobre o estatuto do corpo, fazê-los experimentar no próprio corpo, como um dispositivo de cuidado e aprendizagem, e organizar encontros por intermédio de multiplicadores (pessoas que conduziriam a prática), formando novos multiplicadores para que essas informações, conhecimentos e vivências sejam incorporados às práticas de trabalho. Um processo complexo acerca da sensibilização do corpo requer caráter permanente de cuidado e aprendizagem.

Esses encontros entre profissionais de saúde e multiplicadores da Terapia Através do Movimento (TAM) pretendem explorar uma reflexão sobre a experiência prática e vivencial através da percepção e escuta sensível do corpo, com o foco na experiência sensível e singular

\section{POLÊM!CA | Revista Eletronica da Uer}


de cada um. O sensível aqui não apenas como um lugar no corpo, mas como um dispositivo que nos permite e ensina a sentir e a perceber nosso corpo com mais atenção e cuidado.

Torralba (2009) nos fala sobre a capacidade de estar presente no que somos e no que fazemos, percebendo no contato com o outro como ele nos toca e como tocamos nele, permitindo uma ampliação da senso-percepção, tanto em relação aos outros corpos, como do espaço e de si mesmo.

Para Torralba (2009):

\begin{abstract}
A saúde do corpo depende de um certo grau de abertura às forças do mundo. A consciência de si não é independente da consciência do mundo. Para além da intencionalidade, a consciência não revela os sentidos de seus objetos através da percepção. Ela é invadida pelos elementos do corpo em sua abertura ao mundo. Ocorre assim por osmose ou contágio, onde o corpo encontra um grau de indiscernibilidade com as forças da vida. Experiência de contato que denota como somos seres da superfície, da relação: constituímos-nos no encontro (TORRALBA, 2009, p. 54).
\end{abstract}

No trabalho de conscientização do movimento, que a Terapia Através do Movimento propõe, as pequenas percepções sobre o corpo são trabalhadas e evidenciadas. Movimentos micros produzem grandes transformações e deslumbramentos sobre o próprio corpo. Neste trabalho, criamos uma atenção sutil aos movimentos internos, movimentos externos, movimentos visíveis e invisíveis, sentimos as qualidades do movimento, como o sangue que percorre todo nosso corpo, o coração que pulsa, os pulmões que se expandem, que se retraem e os micromovimentos do aparelho digestivo.

O trabalho de conscientização através do movimento possibilita a atenção aos ruídos internos do corpo, a fim de construir outra qualidade de consciência e presença. Esse trabalho sutil atravessa o corpo organizado, as vísceras, os músculos, os ossos e a pele, abrindo possibilidades de se criar outro lugar para nosso corpo, e acessar outros acontecimentos. Esse trabalho nos leva a um estado de presença diferente do que já estamos acostumados (RESENDE, 2008).

Ao experimentar essa prática na pós-graduação em Terapia Através do Movimento na Faculdade e Escola Angel Vianna nos anos de 2012 e de 2013, registro minhas sensações numa espécie de diário de campo ${ }^{2}$, no qual escrevo sobre essa pesquisa do corpo tão inventiva

\footnotetext{
${ }^{2}$ Diário de campo é um instrumento de análise que auxilia a reflexão.
}

\title{
POLÊM!CA | Revista Eletronica da Ueri
}


experimentada em mim, em um processo que defendemos como importante na formação de multiplicadores da TAM:

Conhecer meus pés, ossinhos, articulações, apoios, colocar meus dedos entre eles e brincar. Brincar com os dedos das mãos nos dedos dos pés e inventar movimentos, micro movimentos que impulsionam a vida com força, e continuar brincando com os bancos, com o espaço, com o próprio corpo e com o olhar. Com outros olhares. Escutar bocejos, o barulho dos bancos o que há de externo e o nosso próprio corpo, o corpo dos outros, a música que se fazia a partir dos movimentos e toda essa relação. Respirar, sorrir, brincar, viver, conhecer um corpo tão presente e muitas vezes desconhecido. Inventar novos modos de se relacionar com o corpo, com o mundo e com o outro. (Diário de campo, 19/05/2012).

A partir dessas experiências que propomos, entendemos que há uma potência infinita nas intensidades afetivas, sensíveis e perceptíveis que atravessam o corpo e possibilitam sair do plano da representação e partir para o plano da criação à medida que nos conectamos com o que sentimos.

Contudo, esse processo que é ao mesmo tempo encantador pode ser também angustiante. Por isso é preciso prudência, pois somos atravessados por formas e intensidades diversas. De acordo com Resende (2008) é imprescindível respeitar o ritmo interno e os limites de cada um. Com o tempo, o corpo vai se tornando mais disponível para o processo que amplia a senso percepção e a propriocepção.

A Terapia Através do Movimento como prática de si deve ser cuidadosamente elaborada e praticada num caminho contínuo, ao longo de toda a vida. Resende (2008) nos aponta que o trabalho corporal não deve operar no tempo do imediato, impondo um ritmo alheio ao do paciente, mas como um processo terapêutico que possa ser sentido pelo paciente, como algo que lhe pertence. Somente deste modo será possível expandir o corpo na direção do aumento da potência e da qualidade de vida.

Relacionar-se com o próprio corpo é acordá-lo para o cotidiano. É preciso desestruturá-lo, para construir um novo olhar, criar novos padrões, novos códigos, não mais aquele código que nos deram quando nascemos e que vamos repetindo ao longo da vida, mas outra forma de nos relacionarmos e estarmos no mundo. Esse processo de sensibilização exige tempo e prudência, porque despertar o corpo é já interferir nele, criando um novo corpo, com novas conexões (RESENDE, 2008).

Nesta prática corporal oferecemos meios para que a pessoa reconheça o seu corpo, nas suas múltiplas dimensões: estruturas, forma, peso, volume, assimetrias, limitações e 
possibilidades de movimento, e o que mais puder ser explorado para construir a noção do todo.

De acordo com Resende (2008):

\begin{abstract}
Quando começamos a despertar e abrir espaços no corpo, a busca por novas possibilidades de movimento vai-se transformando numa necessidade diária para conquistar um corpo mais livre e capaz de se integrar com as suas sensações. Aguçar a capacidade proprioceptiva é poder ir ao encontro da nossa singularidade, (re) conhecendo os limites, capacidades, memórias e vivências do corpo, respeitando-os. Trata-se de um processo de (re) encontro com o corpo no seu eixo global, uma (re) educação-terapêutica que torna o indivíduo autônomo de seu movimento. (RESENDE, 2008, p.163).
\end{abstract}

Partindo dessa concepção que consideramos ampliada e afirmativa de saúde, a Terapia Através do Movimento se configura como uma prática terapêutica para qualquer pessoa que queira, a partir do movimento, estar mais potente nas suas relações consigo mesma e com o mundo.

A proposta da Terapia Através do Movimento é de trabalhar com um corpo possível, ou seja, cada indivíduo realizará os movimentos que seu corpo lhe permite e ampliará suas possibilidades de uso do corpo dentro de seus próprios limites. Esse método pode ser aplicado em qualquer pessoa, inclusive nos casos mais particulares como de um diabético, um hipertenso, um psicótico, um deficiente físico ou mental...

Segundo Resende (2008), o trabalho de conscientização através do movimento, já tem sido aplicado nos campos da promoção da saúde, da reeducação do movimento, da reabilitação (neuromotora, doenças crônicas como hipertensão e diabetes, saúde mental, entre outros). Acredita-se que essa aplicação terapêutica é eficaz, consistente, potente e potencializadora.

\title{
Considerações Finais
}

A Terapia Através do Movimento legitima-se como um importante instrumento terapêutico, produtor de saúde capaz de tornar as relações mais humanizadas e acolhedoras a partir de uma concepção ampliada de saúde, ocupando uma posição política valorizada pelo SUS nos últimos anos, enquanto prática de saúde alternativa ao modelo biomédico dominante.

A Terapia Através do Movimento colabora para a promoção da saúde e da qualidade de vida por propor um conhecimento experiencial do corpo que deve ser conquistado através

\section{POLÊM!CA | Revista Eletronica da Ueri}


da escuta e da pesquisa do movimento, reestabelecendo e recriando o uso do próprio corpo com conforto e com integração psicofísica.

De acordo com Resende (2008), o SUS define essas práticas como tecnologias eficazes que atuam por recursos capazes de estimular os mecanismos naturais de promoção e recuperação da saúde, com ênfase na escuta acolhedora, no desenvolvimento do vínculo terapêutico e na integração do indivíduo com o meio e com os outros.

Portanto, concluímos que a Terapia Através do Movimento pode ser entendida como um instrumento terapêutico nos campos das Práticas Integrativas e Complementares em Saúde no SUS por ter como objetivo a promoção de uma maior integração somatopsíquica, identificando e ressignificando padrões corporais na direção da harmonização e da saúde, estimulando a criatividade de cada um em seu caminho de autonomia. A TAM produz bemestar e o sentimento de que o corpo está vivo, acordado apesar de suas limitações.

\section{Referências}

BRASIL. Ministério da Saúde. Saúde da Família: uma estratégia para a reorientação do modelo assistencial. Brasília, 1997.

. Ministério da Saúde. Política Nacional de Práticas Integrativas e Complementares no SUS. 2006. Disponível em: <http://bvsms.saude.gov.br/bvs/publicacoes/pnpic.pdf>. Acesso em: 15 Nov. 2014

Ministério da Saúde. Cartilha da Política Nacional de Humanização. 2010. Disponível em: <http://bvsms.saude.gov.br/bvs/publicacoes/caderno_textos_cartilhas_politica_humanizacao.pdf >. Acesso em: 15 Nov. 2014

BULHÕES, Barbara G. Consciência do Movimento segundo Angel Vianna: uma prática para o atorcriador. 2009. Trabalho de Conclusão de Curso. Tecnologia em Artes Dramáticas, Centro Universitário da Cidade do Rio de Janeiro, Rio de Janeiro, 2009.

CAETANO, Patrícia; RESENDE, Catarina; TORRALBA, Ruth. Micropolítica do corpo e o devir-dançarina. Polêm!ca, v. 10, n. 4, out/dez 2011. Disponível em: <http://www.epublicacoes.uerj.br/index.php/polemica/article/view/2972>. Acesso em: 25 Mai. 2015.

IMBASSAÍ, Maria Helena. Sensibilidade no cotidiano: conscientização corporal. Rio de Janeiro: Editora UAPÊ, 2006.

. Conscientização corporal: sensibilidade e consciência no mundo contemporâneo. In: CALAZANS, Julieta; CASTILHO, Jacyan; GOMES, Simone. Dança e Educação em movimento. São Paulo: Editora Cortez, 2003.

NUNES, Clarice. Dança, terapia e educação: caminhos cruzados. In: CALAZANS, Julieta; CASTILHO, Jacyan; GOMES, Simone. Dança e Educação em movimento. São Paulo: Editora Cortez, 2003. 
RESENDE, Catarina Mendes. O que pode um corpo? O método Angel Vianna de Conscientização do Movimento como instrumento terapêutico. Physis Revista de Saúde Coletiva, v.18, n.3, p.563-574, 2008, Rio de Janeiro.

RESENDE, Catarina Mendes. Saúde e corpo em movimento: contribuições para uma formalização teórica e prática do método Angel Vianna de Conscientização do Movimento como um instrumento terapêutico. 2008. Dissertação. Programa de Pós-graduação em Saúde Coletiva, Instituto de Estudos em Saúde Coletiva UFRJ, Rio de Janeiro, 2008.

TORRALBA, Ruth Silva. Sensorial do corpo: via régia ao inconsciente. 2009. Dissertação. Programa de Pósgraduação em Psicologia do Departamento de Psicologia da Universidade Federal Fluminense (UFF), Niterói, 2009.

VIANNA, Angel; CASTILHO, Jacyan. Percebendo o corpo. In: GARCIA, Regina Leite (org). O corpo que fala dentro e fora da escola. Rio de Janeiro, DP \& A., 2002. p. 17-34.

Recebido em: 07/05/2015.

Aceito em: 25/06/2015. 